\title{
A Comparative Peripheral Nerve Conduction Study in Type-2 Diabetics with Symptoms of Polyneuropathy with Age and Sex Matched Normal Subjects
}

\author{
Dr.Komal Mankar ${ }^{1}$, Dr.Bhagya.V ${ }^{2}$, Dr.Suresh.Y.Bondade ${ }^{3}$ \\ ${ }^{I}$ Post Graduate, Department Of Physiology, JJM Medical College, Davangere \\ ${ }^{2}$ Professor, Department Of Physiology, JJM Medical College, Davangere \\ ${ }^{3}$ Professor And HOD, Department Of Physiology, JJM Medical College, Davangere
}

\begin{abstract}
:
Background: Diabetes Mellitus is one among the diseases that affects peripheral nervous system and symptomatic Neuropathy in uncontrolled Diabetes is one of the commonest incapacitating complications. Electro diagnostic tests can be used to detect Diabetic Neuropathy at an early stage (before development of the signs or symptoms of Neuropathy). Nerve Conduction Study (NCS) is considered to be the most sensitive, reliable, non-invasive and objective means of investigations of Diabetic Polyneuropathy. Diabetic Neuropathy is curable, and hence if detected, the proper treatment can be instituted in early stages, which again, can give rise to good outcome. As the peripheral nerve has the ability to regenerate, line of treatment can be planned. Aims \& Objectives: To compare and analyze the peripheral nerve conduction studies in symptomatic diabetic neuropathy cases with age and sex matched normal subjects emphasizing on use of Nerve conduction studies as a diagnostic approach to prevent Severe Neuropathy.

Methods: The study group consists of 9 cases diagnosed with Diabetic neuropathy referred to our neurophysiology lab and control group consists of 9 age and sex matched normal subjects who are nondiabetic, healthy volunteers. Statistical analysis was done using unpaired t-test and 8 out of 9 cases considered for statistical analysis. Motor and Sensory nerve conduction studies conducted in both Upper (Median and Ulnar nerves) and Lower limbs (Tibial and Peroneal nerves) using bipolar surface electrodes with RMS EMG EP MARK-II machine.

Results: There is a definite decrease in amplitude and nerve conduction velocities of both the sensory and motor components, axonal and demyelinating type significantly correlating with higher HBAlc levels. F minimum latencies of Median, Tibial and Peroneal nerves were increased possibly more of demyelinating type of Polyneuropathy.

Conclusion: NCS being a simple, harmless, non-invasive and objective technique along with easy interpretation of results can be used routinely to evaluate the status of nerves in patients with Type 2 Diabetes Mellitus to prevent more disabling state at the earliest.
\end{abstract}

Keywords: Diabetic Polyneuropathy, Nerve Conduction Study(NCS)

\section{Introduction}

Diabetes is fast becoming the epidemic of the 21 st century. The physiological properties of nerve and muscle are usually modified due to pathophysiological changes resulting from many diseases like diabetes. ${ }^{[1]}$ The number of people with diabetes has risen from 108 million in 1980 to 422 million in 2014 ' The global prevalence of diabetes among adults over 18 years of age has risen from $4.7 \%$ in 1980 to $8.5 \%$ in 2014. Diabetes prevalence has been rising more rapidly in middle- and low-income countries. Diabetes is a major cause of blindness, kidney failure, heart attacks, stroke and lower limb amputation. In 2012, an estimated 1.5 million deaths were directly caused by diabetes and another 2.2 million deaths were attributable to high blood glucose. Almost half of all deaths attributable to high blood glucose occur before the age of 70 years ${ }^{[2]}$ WHO projects that diabetes will be the 7th leading cause of death in $2030 .{ }^{[3]}$ Healthy diet, regular physical activity, maintaining a normal body weight and avoiding tobacco use are ways to prevent or delay the onset of type 2 diabetes. Diabetes can be treated and its consequences avoided or delayed with diet, physical activity, medication and regular screening and treatment for complications ${ }^{[2]}$ Diabetes Mellitus is one among the diseases that affects peripheral nervous system and symptomatic Neuropathy in uncontrolled Diabetes is one of the commonest long term incapacitating complications. A widely accepted definition of diabetic peripheral neuropathy is "the presence of symptoms and/or signs of peripheral nerve dysfunction in people with diabetes after exclusion of other causes. Many previous studies have reported a wide range of prevalence of Neuropathy in Diabetics which estimates from $3 \%$ to $32 \% .{ }^{[4]}$ Nerve problems in diabetes mellitus can develop at any time, often occurring 
about 10 years after the diagnosis of diabetes. Longer the duration of diabetes and irregular being the treatment, with fluctuating blood sugar levels, higher will be the risk of developing diabetic neuropathy.

Nerve conduction studies (NCS) and electromyography (EMG) can document the characteristics of the neuropathy (e.g., axonal,demyelinating) and the localisation (e.g.mononeuropathy versus radiculopathy or distal neuropathy) and, possibly, the severity and even prognosis for morbidity. Multiple consensus panels recommend the inclusion of electrophysiological testing in the evaluation of diabetic neuropathy. These same panels recommend the use of NCV/EMG procedures in clinical research studies.

NCS/EMG establishes diagnosis quiet early than other diagnostic procedures because of its sensitivity to detect slowing of conduction of action potential in a nerve, which is an early indicator of peripheral neuropathy. Neurophysiologic studies supplemented the clinical examination by precisely localizing the lesion and characterizing the conduction abnormalities providing additional information, details and objectivity. They delineate a variety of conditions that may otherwise escape detection. ${ }^{[5]}$

Mostly NCV determination is used compared to EMG for purpose of studying diabetic neuropathy due to

following advantages:

1. It is easily obtainable.

2. It is painless and harmless.

3. It provides a good recording.

4. It is easily reproducible and sensitive.

5. It gives a clear recording with minimal disturbances.

6. Not much of amplification is required.

7. Early functional impairment of nerve in asymptomatic cases can be studied i.e.disorder affecting the nerves insufficient to produce clinical abnormality may be detected as decrease in Sensory NCV.

8. Useful as a tool of diagnostic, prognostic and follow up study of Neuropathy. ${ }^{[6]}$

\section{Materials and Methods}

Motor and sensory nerve conduction studies were conducted in both upper (Median and Ulnar nerves) and lower limbs (Tibial and Peroneal nerves) using bipolar surface electrodes in 9 Type-2 Diabetics with symptoms of neuropathy referred to our neurophysiology lab for NCS and 9 healthy volunteers (age and sex matched) after taking informed consent. NCS was performed with RMS EMG EP MARK II machine and temperature of the lab was maintained at $21-23^{\circ} \mathrm{C}$.

Latency, Amplitude, conduction velocity and F-wave studies were done by placing the active electrode over the motor point and reference electrode on the tendon with stimulation proximally and distally. Both active and reference electrodes are placed on the nerve in sensory nerve studies with Ground electrode between stimulating and recording electrode.

Values taken as reference from normal values of motor and sensory nerve conduction from study by Misra and Kalita. Motor nerve conduction studies were carried out by placing active electrode over the motor point and reference electrode on the tendon by stimulating proximally and distally. Sensory nerve conduction studies were carried out with both active and reference electrode placed on the nerve. Ground electrode is placed between stimulating and recording electrode.

\section{Motor nerve conduction studies ${ }^{[7]}$ \\ Median motor nerve conduction-}

Recording electrode is placed close to the motor point of abductor pollicis brevis and reference electrode $3 \mathrm{~cm}$ distal at first metacarpophalangeal joint. A supramaximal stimulation is given at wrist $(3 \mathrm{~cm}$ proximal to the distal crease) and at elbow (near the volar crease of the brachial pulse)

\section{Ulnar motor nerve conduction}

Recording is usually done from Abductor digiti minimi employing surface electrodes with stimulation at wrist and elbow. Ulnar nerve slides back and forth on extension and flexion of elbow, therefore a standard position of elbow with $90^{\circ}$ or $135^{\circ}$ flexion during stimulation and measurement of distance is recommended. (Harding and Haler, 1983)

\section{Peroneal nerve conduction}

Surface recordings are obtained from extensor digitorum brevis and stimulation is given at ankle and at the neck of fibula.

\section{Tibial nerve conduction}

The active surface recording electrode is placed on abductor hallucis or abductor digiti quinti slightly below and anterior to navicular tuberosity. Surface stimulation is used behind and proximal to the medial 
malleolus and in the popliteal fossa along the flexor crease of the knee slightly lateral to midline in popliteal fossa.

\section{Sensory nerve conduction studies ${ }^{[7]}$}

Median sensory nerve conduction-

The recording electrode for orthodromic conduction is placed $3 \mathrm{~cm}$ proximal to the distal crease and reference is placed at a distance of $3 \mathrm{~cm}$ proximally. For stimulation, ring electrodes are placed at the second or third digits. The cathode is placed at first interphalangeal joint and anode $3 \mathrm{~cm}$ distal.

\section{Ulnar sensory nerve conduction}

The orthodromic conduction was done by stimulating the digital nerve by ring electrodes at interphalangeal joint of fifth digit.

\section{Superficial Peroneal nerve conduction}

Active electrode is placed just above the junction of lateral third of a line connecting the malleoli, and reference electrode $3 \mathrm{~cm}$ distal to the active electrode. Antidromic surface stimulation is carried out $10-15 \mathrm{~cm}$ proximal to the upper edge of lateral malleolus anterior to peroneus longus

\section{Sural nerve conduction}

The surface electrode between lateral malleolus and tendoachilles records sural nerve conduction. The nerve is stimulated antidromically $10-16 \mathrm{~cm}$ proximal to the recording electrode, distal to lower border of gastrocnemius at the junction of middle and lower third of leg.

\section{Statistical analysis and results}

Statistical analysis was done using unpaired t-test. 8 out of 9 cases were considered for analysis as the case being a Severe debilitating neuropathy, no response was obtained on both motor and sensory nerve stimulation even with supramaximal strength of stimulation

\begin{tabular}{|l|l|l|l|}
\hline $\begin{array}{l}\text { Socio-demographic } \\
\text { characteristics }\end{array}$ & Cases N=8 & Controls N=9 \\
\hline Age (Mean \& Sd) & $50.44 \pm 11.45$ & $50.44 \pm 11.45$ \\
\hline \multirow{2}{*}{ Sex } & Male & $5(62.5 \%)$ & $5(55.5 \%)$ \\
\cline { 2 - 4 } & Female & $3(37.5 \%)$ & $4(44.5 \%)$ \\
\hline
\end{tabular}

Table 1- Distribution of cases and controls showing 8 cases and 9 controls analysed statistically

\begin{tabular}{|c|c|c|c|c|c|c|}
\hline & & Mean & $\begin{array}{l}\text { Std } \\
\text { deviation }\end{array}$ & Mean & Std deviation & \\
\hline Nerve & & Cases & & Contr & & Unpaired t test \\
\hline Rt Median & Latency (ms) & 4.21 & 0.94 & 3.27 & 0.57 & $2.52, \mathrm{P}<0.02$ \\
\hline & Amplitude (mV) & 4.24 & 2.70 & 10.09 & 3.04 & $4.18, \mathrm{P}<0.000$ \\
\hline & $\mathrm{CV} \mathrm{m} / \mathrm{s}$ & 45.56 & 8.74 & 56.93 & 3.48 & $3.60, \mathrm{P}<0.003$ \\
\hline & $\begin{array}{l}\text { F minimum latency } \\
(\mathrm{ms})\end{array}$ & 32.38 & 5.98 & 24.11 & 9.13 & $1.95, \mathrm{P}<0.05$ \\
\hline Lt.Median & Latency (ms) & 5.87 & 3.11 & 2.94 & 0.85 & $2.73, \mathrm{P}<0.01$ \\
\hline & Amplitude (mV) & 3.15 & 2.61 & 7.32 & 2.98 & $3.04, \mathrm{P}<0.008$ \\
\hline & $\mathrm{CV} \mathrm{m} / \mathrm{s}$ & 49.51 & 6.83 & 57.79 & 2.98 & $3.31, \mathrm{P}<0.005$ \\
\hline & $\begin{array}{l}\text { F minimum latency } \\
(\mathrm{ms})\end{array}$ & 28.47 & 6.49 & 27.41 & 0.98 & $0.52, \mathrm{NS}$ \\
\hline Rt.Ulnar & Latency (ms) & 3.32 & 0.85 & 3.91 & 0.91 & $1.38, \mathrm{NS}$ \\
\hline & Amplitude (mV) & 4.95 & 4.84 & 5.21 & 3.02 & $0.13, \mathrm{NS}$ \\
\hline & $\mathrm{CV} \mathrm{m} / \mathrm{s}$ & 52.64 & 7.77 & 51.84 & 3.72 & $0.28, \mathrm{NS}$ \\
\hline & $\begin{array}{l}\text { F minimum latency } \\
(\mathrm{ms})\end{array}$ & 33.03 & 4.41 & 47.97 & 6.40 & $4.19, \mathrm{P}<0.001$ \\
\hline Lt. Ulnar & Latency $(\mathrm{ms})$ & 3.27 & 0.84 & 5.93 & 1.41 & $4.39, \mathrm{P}<0.001$ \\
\hline & Amplitude (mV) & 4.19 & 2.94 & 3.46 & 1.73 & $0.62, \mathrm{NS}$ \\
\hline & $\mathrm{CV} \mathrm{m} / \mathrm{s}$ & 47.60 & 10.26 & 47.09 & 4.75 & $0.13, \mathrm{NS}$ \\
\hline & $\begin{array}{l}\text { F minimum latency } \\
(\mathrm{ms})\end{array}$ & 32.70 & 7.63 & 48.94 & 5.66 & $4.38, \mathrm{P}<0.001$ \\
\hline
\end{tabular}

Table 2- Mean of Distal motor latencies, Amplitude of CMAP, CV, F minimum latency of Rt. \& Lt Median nerves and Rt.\& Lt.Ulnar nerves with $\mathrm{p}$ values 
A Comparative Peripheral Nerve Conduction Study In Type-2 Diabetics with Symptoms Of

\begin{tabular}{|c|c|c|c|c|c|c|}
\hline \multicolumn{2}{|l|}{ Motor Nerve } & \multicolumn{2}{|l|}{ Cases } & \multicolumn{2}{|c|}{ Controls } & \multirow{2}{*}{$\begin{array}{l}\begin{array}{l}\text { Unpaired } \\
\text { test }\end{array} \\
2.25, \mathrm{P}<0.04\end{array}$} \\
\hline Deep Peroneal & Latency (ms) & \begin{tabular}{|l|} 
Mean \\
5.44 \\
\end{tabular} & $\begin{array}{l}\text { Std deviation } \\
1.78 \\
\end{array}$ & $\begin{array}{l}\text { Mean } \\
3.91\end{array}$ & $\begin{array}{l}\begin{array}{l}\text { Std } \\
\text { deviatio } \\
\text { n }\end{array} \\
0.91\end{array}$ & \\
\hline & Amplitude (mV) & 2.67 & 2.37 & 5.21 & 3.02 & $1.91, \mathrm{NS}$ \\
\hline & $\mathrm{CV} \mathrm{m} / \mathrm{s}$ & 38.18 & 9.38 & 51.84 & 3.72 & $4.04, \mathrm{P}<0.001$ \\
\hline & F minimum latency (ms) & 65.27 & 10.10 & 47.97 & 6.40 & $3.55, \mathrm{P}<0.005$ \\
\hline Tibial & Latency (ms) & 5.82 & 1.13 & 5.68 & 1.37 & $0.21, \mathrm{NS}$ \\
\hline & Amplitude (mV) & 1.73 & 0.91 & 3.66 & 1.63 & $2.65, \mathrm{P}<0.01$ \\
\hline & $\mathrm{CV} \mathrm{m} / \mathrm{s}$ & 39.48 & 7.27 & 48.64 & 5.47 & $2.95, \mathrm{P}<0.01$ \\
\hline & F minimum latency (ms) & 52.88 & 15.52 & 48.94 & 5.66 & $0.69, \mathrm{NS}$ \\
\hline
\end{tabular}

Table 3- Mean of Distal motor latencies, Amplitude of CMAP, CV, F minimum latency of Deep peroneal and Tibial nerves with $\mathrm{p}$ values

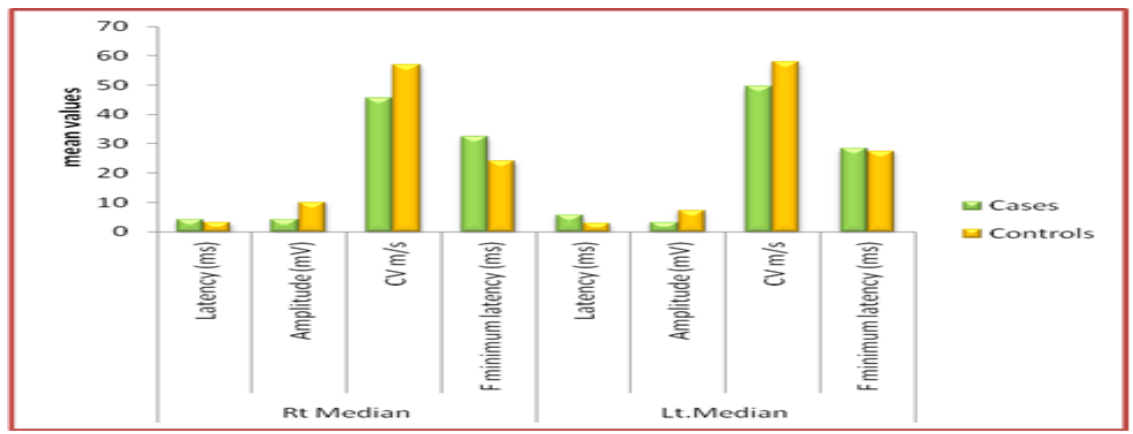

Figure 1-Mean values of Rt. \& Lt Median motor nerve conduction

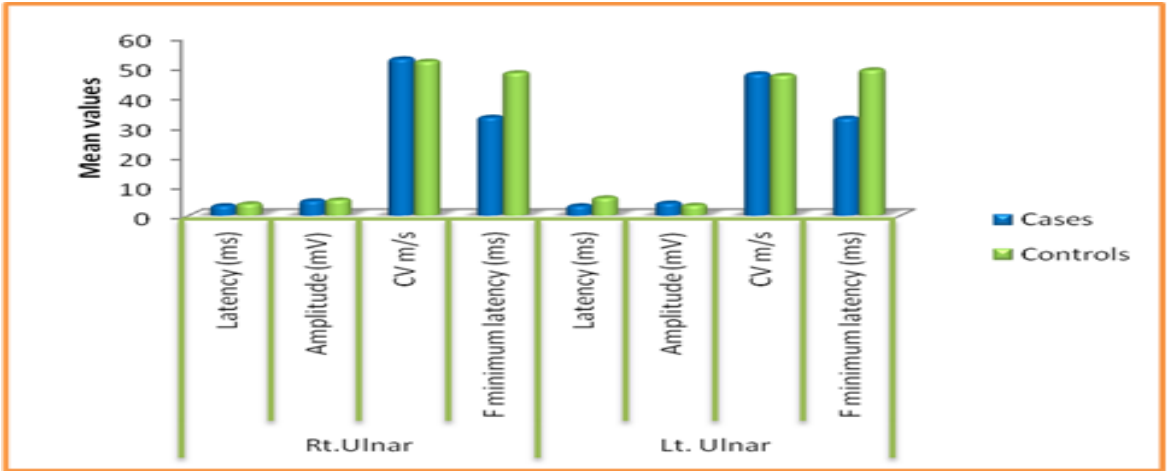

Figure 2- Mean values of Rt. \& Lt.Ulnar motor nerve conduction

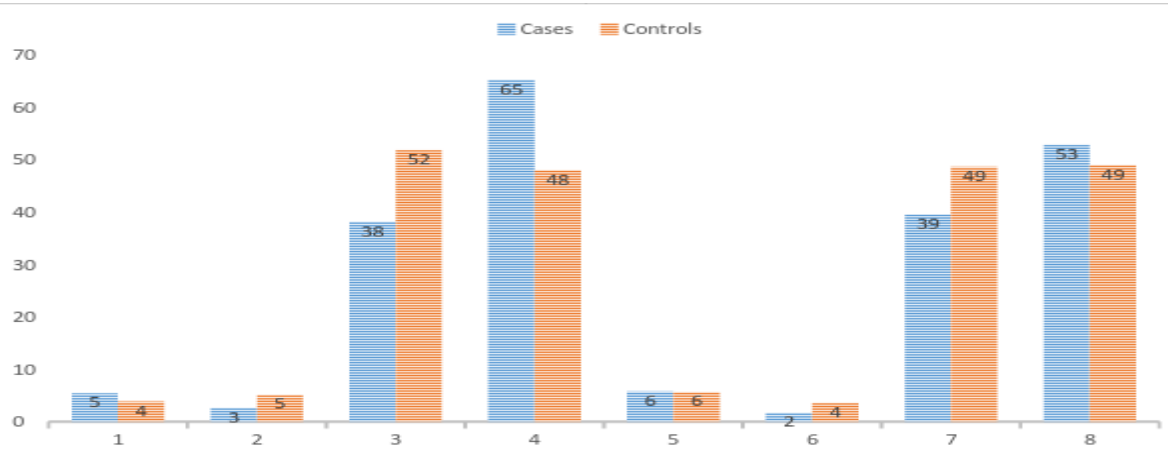

Figure 3-Mean values of Deep peroneal and Tibial motor nerve conduction

\begin{tabular}{|l|l|l|l|}
\hline \multicolumn{2}{|l|}{ F wave response } & \multicolumn{2}{|l|}{$\begin{array}{l}\text { Cases } \\
\text { N=8 }\end{array}$} \\
\cline { 3 - 4 } \multicolumn{2}{|l|}{} & Response & No Response \\
\hline \multirow{2}{*}{ Median } & Rt & $6(75)$ & $2(25)$ \\
\cline { 2 - 4 } & Lt & $3(37.5)$ & $5(62.5)$ \\
\hline \multirow{2}{*}{ Ulnar } & Rt & $4(50)$ & $4(50)$ \\
\cline { 2 - 4 } & Lt & $4(50)$ & $4(50)$ \\
\hline
\end{tabular}




\begin{tabular}{|l|l|l|l|}
\hline Deep peroneal & $\mathrm{Rt}$ & $2(25)$ & $6(75)$ \\
\cline { 2 - 4 } & $\mathrm{Lt}$ & $1(12.5)$ & $7(87.5)$ \\
\hline \multirow{2}{*}{ Tibial } & $\mathrm{Rt}$ & $5(62.5)$ & $3(37.5)$ \\
\cline { 2 - 4 } & $\mathrm{Lt}$ & $6(75)$ & $2(25)$ \\
\hline
\end{tabular}

Table 4-F wave responses of the nerves and the cases

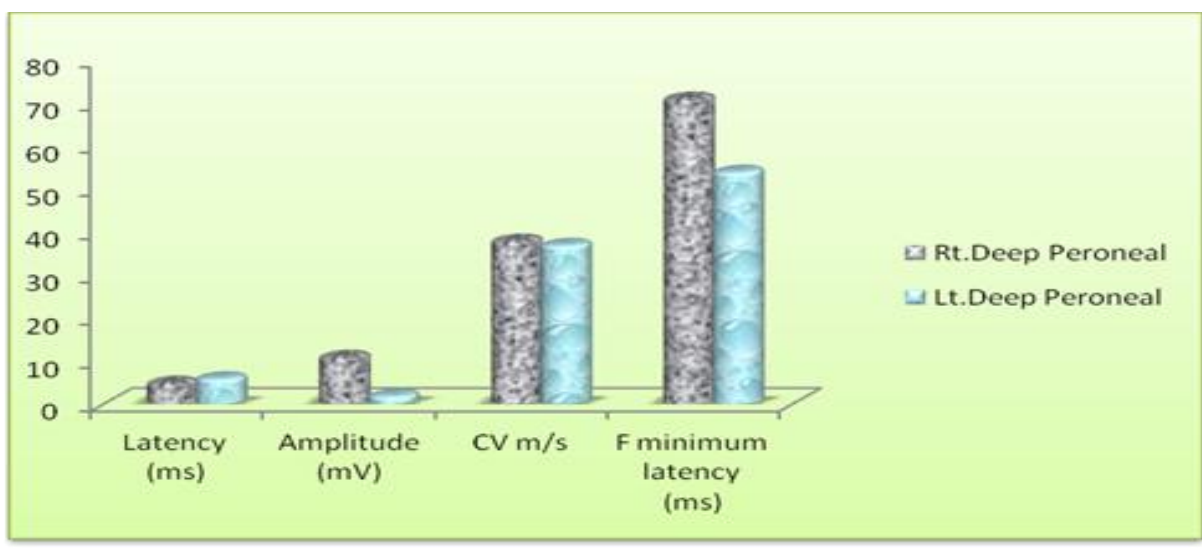

Figure 4-comparision of latency, amplitude,CV and F minimum latencies of Rt.\& Lt Deep Peroneal nerves

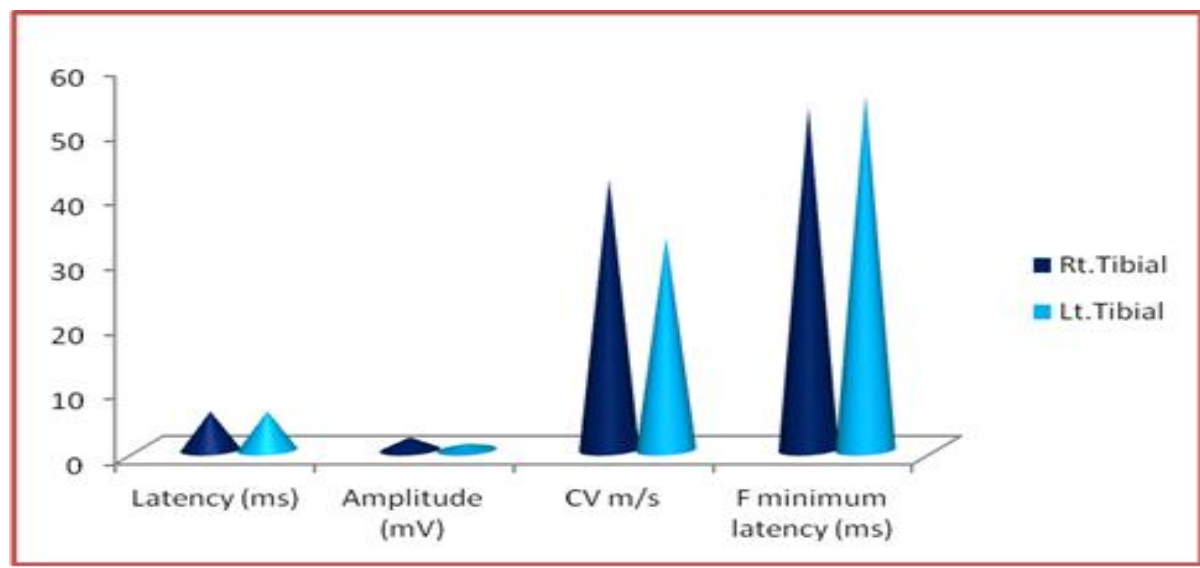

Figure 5-comparision of latency, amplitude, CV, F minimum latencies in Rt.\& Lt Tibial nerves Sensory nerve conduction studies

\begin{tabular}{|c|c|c|c|c|c|c|}
\hline \multicolumn{2}{|c|}{ Sensory Nerve } & \multicolumn{2}{|l|}{ Cases } & \multicolumn{2}{|c|}{ Controls } & \multirow[t]{2}{*}{ Unpaired $t$ test } \\
\hline & & Mean & Std deviation & Mean & Std deviation & \\
\hline \multirow[t]{3}{*}{ Rt. Median } & Latency (ms) & 3.98 & 1.48 & 2.65 & 0.50 & $2.55, \mathrm{P}<0.02$ \\
\hline & Amplitude (mV) & 23.39 & 24.74 & 41.73 & 14.64 & $1.89, \mathrm{NS}$ \\
\hline & $\mathrm{CV} \mathrm{m} / \mathrm{s}$ & 36.86 & 9.50 & 58.51 & 6.39 & $5.57, \mathrm{P}<0.000$ \\
\hline \multirow[t]{3}{*}{ Lt. Median } & Latency (ms) & 4.19 & 1.51 & 2.86 & 0.96 & $2.18, \mathrm{P}<0.04$ \\
\hline & Amplitude (mV) & 19.06 & 14.31 & 49.10 & 49.11 & $1.66, \mathrm{NS}$ \\
\hline & $\mathrm{CV} \mathrm{m} / \mathrm{s}$ & 37.67 & 10.79 & 57.09 & 10.55 & $3.74, \mathrm{P}<0.002$ \\
\hline \multirow{3}{*}{ Rt. Ulnar } & Latency (ms) & 3.63 & 1.62 & 5.51 & 1.29 & $2.58, \mathrm{P}<0.02$ \\
\hline & Amplitude (mV) & 16.43 & 12.10 & 5.74 & 4.81 & $2.43, \mathrm{P}<0.02$ \\
\hline & $\mathrm{CV} \mathrm{m} / \mathrm{s}$ & 37.63 & 12.34 & 47.27 & 8.94 & $1.82, \mathrm{NS}$ \\
\hline \multirow[t]{3}{*}{ Lt. Ulnar } & Latency (ms) & 3.61 & 0.72 & 2.06 & 0.15 & $6.30, \mathrm{P}<0.000$ \\
\hline & Amplitude (mV) & 31.04 & 58.53 & 16.34 & 4.38 & $0.75, \mathrm{NS}$ \\
\hline & $\mathrm{CV} \mathrm{m} / \mathrm{s}$ & 38.29 & 8.61 & 56.16 & 3.08 & $5.84, \mathrm{P}<0.000$ \\
\hline
\end{tabular}

Table 5-Latency, Amplitude and CV of upper limb nerves and $p$ values

\begin{tabular}{|c|l|l|l|l|l|l|}
\hline \multirow{2}{*}{ Sensory Nerve } & \multicolumn{2}{l|}{ Cases } & Controls & \multirow{2}{*}{$\begin{array}{l}\text { Unpaired t } \\
\text { test }\end{array}$} \\
\cline { 3 - 7 } & Mean & $\begin{array}{l}\text { Std } \\
\text { deviation }\end{array}$ & Mean & $\begin{array}{l}\text { Std } \\
\text { deviation }\end{array}$ & \\
\hline \multirow{2}{*}{$\begin{array}{c}\text { Superficial } \\
\text { Peroneal }\end{array}$} & Latency $(\mathbf{m s})$ & 5.90 & 2.23 & 5.51 & 1.29 & $0.49, \mathrm{NS}$ \\
\cline { 2 - 7 } & Amplitude $(\mathbf{m V})$ & 8.44 & 8.76 & 5.74 & 4.81 & $0.78, \mathrm{NS}$ \\
\cline { 2 - 7 } & $\mathbf{C V ~ m / s}$ & 38.25 & 17.24 & 47.27 & 8.94 & $1.36, \mathrm{NS}$ \\
\hline
\end{tabular}




\begin{tabular}{|l|l|l|l|l|l|l|}
\hline Sural & Latency (ms) & 5.81 & 2.49 & 2.06 & 0.15 & $\begin{array}{l}4.66, \\
\mathrm{P}<0.001\end{array}$ \\
\cline { 2 - 7 } & Amplitude (mV) & 10.42 & 9.53 & 16.34 & 4.38 & $1.62, \mathrm{NS}$ \\
\cline { 2 - 7 } & $\mathbf{C V ~} \mathbf{~ m} / \mathbf{s}$ & 29.93 & 9.39 & 56.16 & 3.08 & $\begin{array}{l}7.87, \\
\mathrm{P}<0.000\end{array}$ \\
\hline
\end{tabular}

Table 6- latency,Amplitude and CV of lower limb nerves and $\mathrm{p}$ values

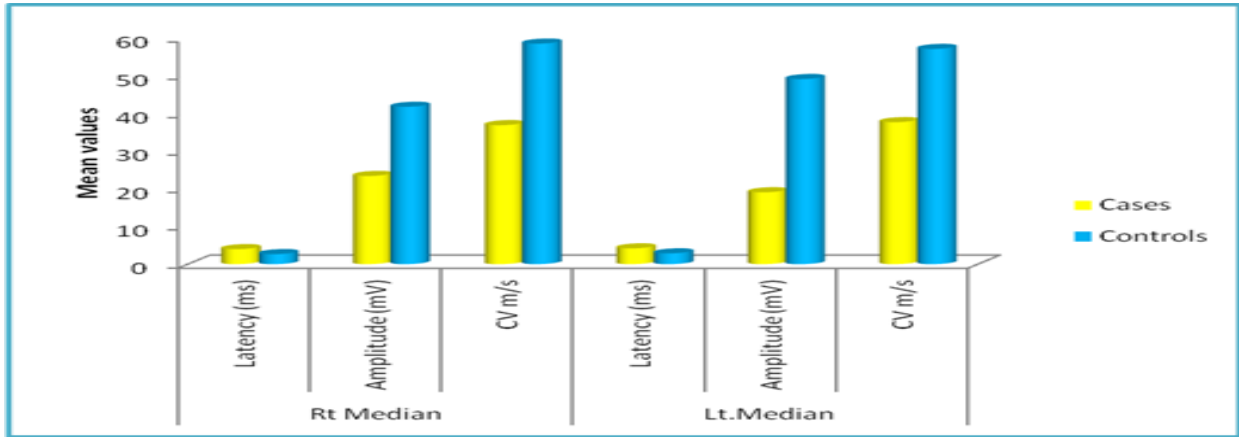

Figure 6-Comparision of sensory nerve conduction values of Rt.\& Lt.Median nerves

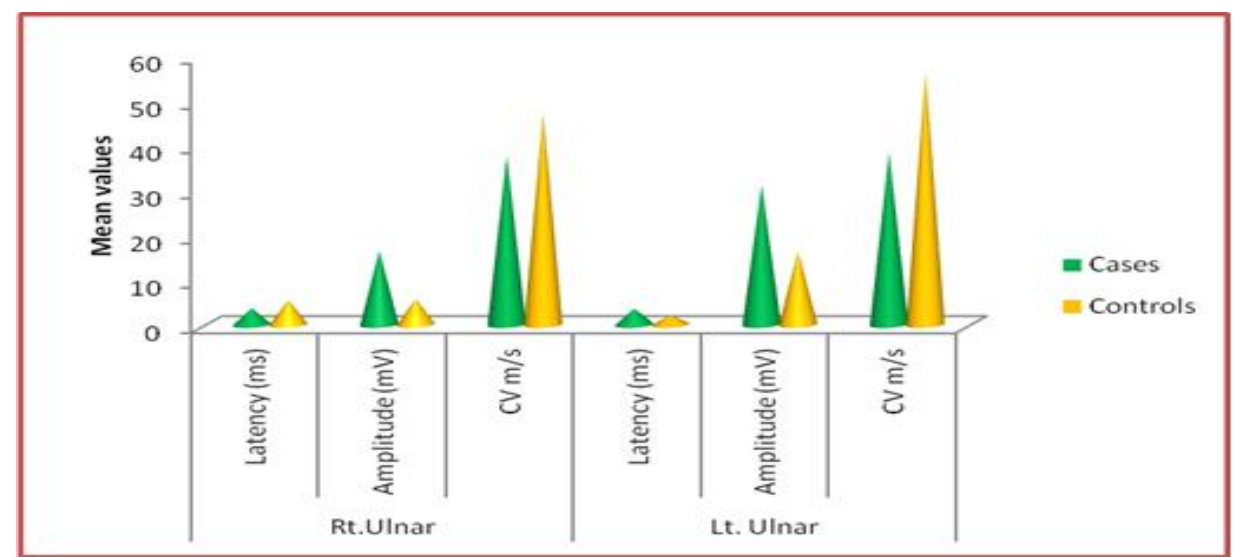

Figure 7-comparision of sensory nerve conduction values of Rt.\& Lt ulnar nerves

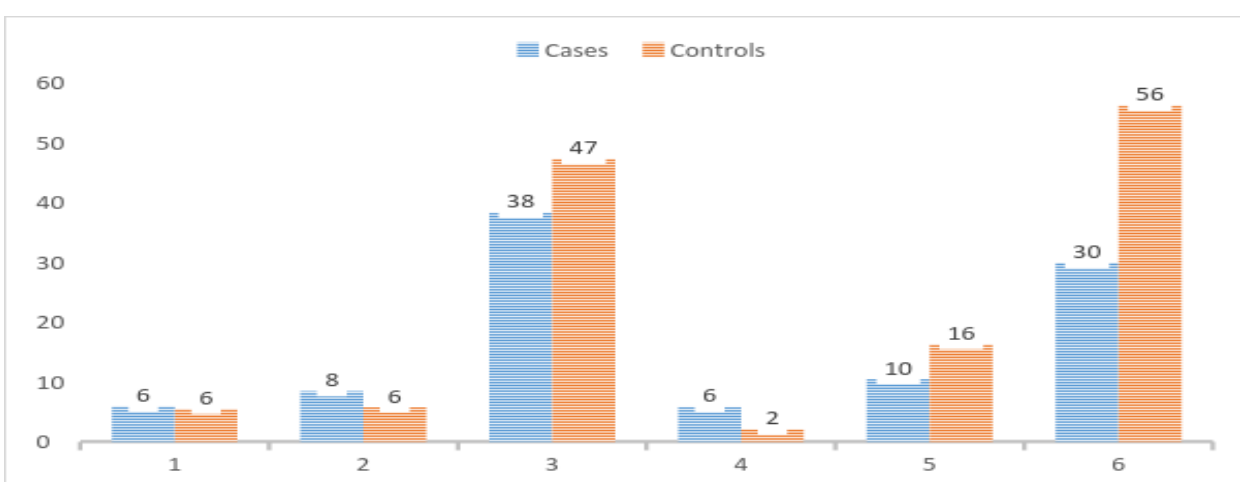

Figure 8-comparision of sensory nerve conduction values of Peroneal and sural nervesz

\section{Motor nerve conduction studies}

Mean of Distal motor latencies of Rt.\& Lt.Median nerves and Tibial and Deep Peroneal nerves in cases were increased significantly in comparision with mean latencies of the nerves in controls $(p<0.02$ and $p<0.04$ respectively). Mean of Amplitude of CMAP (compound muscle action potential) was markedly reduced in Rt.\& Lt.Median nerves and Tibial and Peroneal nerves ( $\mathrm{p}<0.000 ; \mathrm{p}<0.01$ respectively). Mean Motor nerve conduction velocities also reduced significantly in the same nerves. F-wave response was not obtained mostly from the lower limb nerves - esp.,Deep Peroneal nerve. F minimum latencies of Deep Peroneal, Rt.Median, ulnar nerves were increased showing Demyelinating type of Neuropathy 


\section{Sensory nerve conduction studies -}

There is a significant increase in latency, decrease in amplitude and conduction velocity in Median, Sural and Peroneal nerves. No statistical significant difference in mean values of cases and controls. Therefore, the features are mixed varying in different cases, being sensory, motor, axonal \& Demyelinating. 1 case being Severe neuropathy and another case with Median nerve entrapment features.

\section{Discussion}

Results of the present study indicates that there is a definite decrease in amplitude and nerve conduction velocities of both the sensory and motor components, axonal and demyelinating type significantly correlating with higher HBAlc levels and F minimum latencies of Median, Tibial and Peroneal nerves were increased possibly more of demyelinating type of Polyneuropathy. The difference in reduction of SNCV of lower limbs is greater than that in upper limbs, showing that long nerves are comparatively more affected. ${ }^{[8]}$ Conduction abnormalities develop diffusely along the entire length of nerve but more in distal than the proximal segment The NCV is gradually diminished by Diabetic Neuropathy, with estimate of a loss of approximately $0.5 \mathrm{~m} / \mathrm{s} /$ year and a simple rule is that $1 \%$ fall in $\mathrm{HbA} 1 \mathrm{c}$ improves the conduction velocity of about $1.3 \mathrm{~m} / \mathrm{s}$ (Arezzo,1997). Correction of Hyperglycemia in patients results in improvement of symptoms as well as nerve conduction abnormalities (Judzewitsch et al.,1983).Elizabeth et al 1998 volume 245; number 2/Jan 1998 studied about the assessment of neuropathy in diabetic patients by study of the conduction velocity within motor and sensory fibres and came to a conclusion that longer the duration of diabetes, changes in the motor and sensory responses of the individual is certain.

The studies were consistent with previous study done by Muthuselvi $\mathrm{K}$ et.al where in the values of the amplitude of both sensory and motor nerve conduction were found to be significantly reduced in diabetic individuals than the non-diabetic control group with significant 'p' value. It was also seen that on correlating the blood sugar values, there was an inverse relationship, with increasing blood sugar values sensory nerve conduction velocities are correspondingly decreasing and motor nerve conduction velocities too decreasing, though there are fluctuations. ${ }^{[9]}$ but, in our study, correlation of cases with blood sugars was not taken into account although the cases in our study mostly presented with higher HbAlc and blood sugar levels. These studies were also consistent with the previous study done by OLNEY;RICHARD K 1998

Also, the present study was comparable to the study done by Verma et.al who showed that in comparision to normal healthy volunteers, amplitude and conduction velocity range is significantly decreased in diabetic patients ${ }^{[10]}$ and most affected nerve in upper limb being Median nerve and lower limb is sural nerve which is also comparable with study done by Zahed Ali et.al. ${ }^{[8]} \mathrm{A}$ study done by Xuan Kong et al. demonstrated that NCS using a computer based electrodiagnostic equipment was a suitable tool for the diagnosis of Diabetic Polyneuropathy. ${ }^{[11]}$

\section{Conclusion}

From our study, we conclude that increased distal motor latencies, reduced amplitude of CMAP and motor conduction velocities in Median, Tibial, Deep peroneal nerves indicates involvement more of lower limb nerves in the cases referred compared to the age and sex matched normal subjects. F minimum latencies increased showing a demyelinating type of Neuropathy cases with absent F-wave response in most of the lower limb nerves in cases compared to normal subjects. There is a considerable increase in latency, decrease in amplitude of SNAP (sensory nerve action potential) and conduction velocity in the sensory nerves studied in cases although no statistical significant difference in mean values of cases and controls. The features found to be of varying -both sensory and motor involvement, axonal and demyelinating type of neuropathy.

NCS being a simple, harmless, non-invasive and objective technique along with easy interpretation of results can be used routinely to evaluate the status of nerves in patients with Type 2 Diabetes Mellitus to prevent more disabling state at the earliest.

Diabetic Neuropathy is curable, and hence if detected, the proper treatment can be instituted in early stages, which again, can give rise to good outcome. As the peripheral nerve has the ability to regenerate, line of treatment can be planned. Symptoms usually develop at any degree of neuropathic impairment or may not occur at all which indicates the need for doing nerve conduction studies.

Nerve conduction studies may be effectively used to select the most beneficial therapy. Thus, it can be used as reliable tool for detection of Diabetic Polyneuropathy especially for the subclinical neuropathies and a routine NCS should be done on diabetics atleast on yearly basis.

The drawbacks of the nerve conduction study are that: only the status of distal nerves can be evaluated and only the velocities in the large fiber can be measured. These draw backs do not pose any serious problem, since in NIDDM, distal nerves with largest myelinated 'A' fibers are chiefly affected. 
Limitation of our study is small sample size due to which the features could not be delineated at large and reference standard values of nerve conduction parameters are considered from the study done by Misra and Kalita.

\section{References}

[1]. Krarup C. Nerve conduction studies in selected peripheral nerve disorders. Curr Opin Neurol. 2002;15:579-93.

[2]. Global report on Diabetes. World Health Organization. Geneva; 2016.

[3]. Mathers CD, Loncar D. Projections of Global Mortality and Burden of Disease from 2002 to 2030. 2015;3(11).

[4]. Ziegler D, Gries FA, Spuler M, Lessmann F. The epidemiology of diabetic neuropathy: DiaCAN Multicenter Study Group. Diabet Med. 1993;10(suppl.2):82S - 86S

[5]. J Kimura. Long and short of nerve conduction measures: reproducibility for sequential assessments. J NeurolNeurosurgPsychiatry. 2001;71:427.4 30 doi:10.1136/jnnp.71.4.427.

[6]. Wagmen\&lesse. Maximum conduction velocities of motor fibers of ulnar nerve in human subjects of various ages and sizes. $\mathrm{j}$ neurophysiol.may 1 1952; 15(3):235-44.

[7]. U. K. Misra,J Kalita. Clinical Neurophysiology Nerve Conduction Electromyography \& Evoked Potentials. 2nd ed. Elsevier India Pvt.ltd;

[8]. Zahed Ali et.al. Role of Electrodiagnostic tests in Early detection of Diabetic Neuropathy. J Neurosci. 2008;23(1):36

[9]. Muthuselvi K, Shanthi M, Ethiya N. Comparison of Nerve Conduction Studies in Geriatric Normal and Diabetic Subjects. 2015;4(4):2013-5.

[10]. Verma A, Mahajan S, Khadayate P. Sensory Nerve Conduction Studies In Non-Insulin Dependent Diabetes Mellitus ( NIDDM ) Patients Without Symptoms Of Peripheral Neuropathy And Healthy Volunteers : A Comparative Study. 2(1):158-62.

[11]. Kong X, Lesser EA, Potts FA, Gozani SN. Utilization of Nerve Conduction Studies for the Diagnosis of Polyneuropathy in Patients with Diabetes: A Retrospective Analysis of a Large Patient Series. 2008;2(2):268-74. 